\title{
Outcome of Oral and Intra-arterial Nimodipine Administration After Aneurysmal Subarachnoid Haemorrhage - A Single-centre Study
}

\author{
GREGORY EHRLICH ${ }^{1}$, THOMAS KIRSCHNING ${ }^{2}$, HOLGER WENZ $^{3}$, ALDEMAR ANDRES HEGEWALD ${ }^{4}$, \\ EVA NEUMAIER-PROBST ${ }^{3}$ and MARCEL SEIZ-ROSENHAGEN ${ }^{1}$ \\ ${ }^{1}$ Department of Neurosurgery, Medical Faculty Mannheim, University of Heidelberg, Mannheim, Germany; \\ ${ }^{2}$ Department of Anaesthesiology and Surgical Intensive Care Medicine, \\ Medical Faculty Mannheim, University of Heidelberg, Mannheim, Germany; \\ ${ }^{3}$ Department of Neuroradiology, Medical Faculty Mannheim, University of Heidelberg, Mannheim, Germany; \\ ${ }^{4}$ Department of Neurosurgery, HELIOS Ostsee Hospital Damp, Ostseebad Damp, Germany
}

\begin{abstract}
Background: Oral nimodipine is administered to improve clinical outcome in patients with aneurysmal subarachnoid hemorrhage (aSAH). In this study, clinical outcome in patients with and without oral nimodipine administration was assessed. Materials and Methods: A total of 105 patients did not receive oral nimodipine but did receive intra-arterial nimodipine in the occurrence of hemodynamically relevant vasospasm after aSAH, whereas 74 patients received applications of both. Demographicl radiological details and clinical presentation were abstracted from the case records. Results: Patient baseline characteristics were comparable, a predominance of endovascular coiling was shown in cohort 2 ( $p=0.0135)$. Severity of initial aSAH and clinical status at admission (Hunt and Hess) was significantly higher in those receiving oral nimodipine. Incidence of angiographic vasospasm was significantly higher in patients not treated with oral nimodipine $(p=0.0305) ; a$ significantly better outcome measured by the National Institute of Health Stroke Scale $(p=0.0213)$, was noted in those receiving oral nimodipine. Conclusion: Oral nimodipine administration improved clinical outcome of patients after aSAH and should be administered routinely for such patients.
\end{abstract}

This article is freely accessible online.

Correspondence to: Gregory Ehrlich, MD, Department of Neurosurgery, Medical University Mannheim, Theodor-Kutzer-Ufer 13, 68167 Mannheim, Germany. Tel: +49 621/383 2360, Fax: +49 621/383 2004, e-mail: gregy.ehrlich@gmx.de/gregory.ehrlich@umm.de

Key Words: Aneurysmal subarachnoid hemorrhage, nimodipine, vasospasm, outcome.
One serious complication after aneurysmal subarachnoid hemorrhage $(\mathrm{aSAH})$ is the incidence of symptomatic vasospasm (1). Angiographic vasospasm is seen in approximately $70 \%$ of these patients between the third and the fourteenth day after the ictus (2). In $20-40 \%$ of all cases, neurological deficits or infarction caused by delayed cerebral ischemia (DCI) will appear (1, 3-5).

The thickness of the blood clot in the basal cisterns and the presence of intraventricular hemorrhage are the main risk factors for the development of DCI (6). Experimental studies have shown that the presence of erythrocytes in the cerebrospinal fluid can trigger vasospasm by the release of superoxide anions (7-9). Other risk factors are poor clinical grade (10), hypertension (acute or chronic) (10), fever (10) and cigarette smoking (11). In addition, younger age seems to be a predictor for the development of symptomatic vasospasm (12).

Several methods have been developed to minimize the occurrence of vasospasm. One of these is medication with vasodilatory substances such as calcium antagonists or magnesium sulphate. Magnesium sulphate leads to no improvement in the overall outcome in patients with aSAH (1315). Nimodipine, a dihydropyridine calcium antagonist, blocks the calcium influx through L-type calcium channels. Studies have shown a positive effect on the prevention of DCI and on clinical outcome in patients with aSAH when nimodipine was administered (16-27). Even neuroprotection via reduction of calcium-mediated excitotoxicity is described (28). Nimodipine seems to be a safe and cost-effective treatment that increases life expectancy with low incremental costs.

To date, there has been only one multicenter double-blind placebo-controlled trial analyzing the effect of oral nimodipine on the incidence of DCI and on outcome after aSAH irrespective of clinical severity (21). This study was 
conducted in 1988. At that time, only microsurgical procedures were available to exclude an intracranial aneurysm from the arterial circulation. Since the 1990s, endovascular techniques have been continuously developing. Nowadays, in the majority of cases, endovascular coil embolization of patients with aSAH is preferred (29). Even after aneurysm treatment, intra-arterial vasospasm therapy by application of nimodipine via micro-catheter is possible and has led to positive results (30-33).

Because of the change in the treatment of intracranial aneurysms towards endovascular techniques and the possibility of new promising endovascular techniques for preventing clinically relevant vasospasm, the influence of oral and intra-arterial nimodipine should be reinvestigated in patients with aSAH with regard to the occurrence of macrovasospasm and clinical outcome regardless of clinical severity.

Is the administration of oral nimodipine still relevant in patients after aSAH due to current treatment guidelines?

\section{Patients and Methods}

Patients. Data for patients with aSAH treated at the Department of Neurosurgery, Medical Faculty Mannheim, University of Heidelberg, Germany, between January 2011 and October 2014 were analyzed. To establish the diagnosis of aSAH in all patients, a cranial computed tomographic (CT) scan with a CT-angiography or a lumbar puncture with the presence of blood and xanthochromia in the cerebrospinal fluid was performed. Furthermore, a cerebral angiography was performed to assess the aneurysm architecture for treatment decision and as a baseline investigation.

The patients were divided into two groups. In cohort 1 , within the first $48 \mathrm{~h}$ after ictus, the patients received nimodipine orally on a daily basis (60 mg nimodipine every $4 \mathrm{~h}$ for 3 weeks) and in cases of hemodynamically relevant vasospasm additionally received intraarterial nimodipine via micro-catheter. In cohort 2, patients did not receive oral nimodipine at all, and intra-arterial nimodipine was administered in cases of hemodynamically relevant vasospasm. In 2011 and 2012, patients with aSAH did not receive oral nimodipine according to the Standard Operating Procedure (SOP). At the beginning of January 2013, due to a change in the SOP, all patients with aSAH were treated with oral nimodipine within $48 \mathrm{~h}$ after initial bleeding.

Patients with poor initial condition and withdrawal of treatment or death within the first 3 days, non-aneurysmal spontaneous SAH, SAH caused by arteriovenous malformation or patients without repeated angiography in the treatment course were excluded.

Nimodipine administration. Oral: Nimodipine administration was started within $48 \mathrm{~h}$ after ictus. Nimodipine was given orally as fastrelease tablets containing $30 \mathrm{mg}$ active compound $(60 \mathrm{mg}$ nimodipine every $4 \mathrm{~h}$ for 3 weeks). Tablets were taken with water. For comatose patients, the tablets were crushed and administered via stomach tube.

Intra-arterial: For the intra-arterial application of nimodipine, a $4 \mathrm{~F}$ micro-catheter was used. The micro-catheter was placed in the carotid or vertebral arteries depending on the location of vasospasm at the cervical level. A maximum of two catheters were placed per patient. Nimodipine was diluted in a solution of $0.9 \% \mathrm{NaCl}$ to obtain a $25 \%$ concentration. The dose administered was $1-4 \mathrm{mg}$ (5$20 \mathrm{ml}$ ) per vessel at a maximum rate of $2 \mathrm{ml} / \mathrm{min}$. during the treatment, full heparinization was necessary (partial thromboplastin time $=70-90 \mathrm{~s}$ ). The catheter was left in place for 2-3 days, then repeat angiography was performed.

Clinical management. All patients were under continuous monitoring at the neuro-intensive care unit (ICU), including invasive monitoring of circulation parameters and hourly neurological examination. Most patients were monitored by daily transcranial Doppler (TCD) examination. Comatose patients or patients with an initial hydrocephalus were provided with an external ventricular drainage.

Increase of intracranial hypertension and acute symptomatic intracranial mass effect were primarily treated via external ventricular drainage or with repeated boluses of $20 \%$ mannitol or $23.4 \%$ hypertonic saline. In some cases of medically uncontrollable intracranial pressure problems, decompressive craniectomy or a lumbar drainage was considered.

The aneurysm was treated by clipping or coiling within 48 after the ictus. Follow-up angiography for the evaluation of macrovasospasm and the elimination of aneurysms routinely took place $8 \pm 2$ days after the initial hemorrhage. Angiography was performed earlier in the case of clinical deterioration (other reasons such as hydrocephalus or metabolic imbalance were excluded) or if a significant increase in the mean blood flow ( $\geq 50 \mathrm{~cm} / \mathrm{s}$ within $24 \mathrm{~h}$ for the same vessel), measured by TCD, was noted. Clinical deterioration was defined as new neurological deficit (aphasia, palsy) or progressive agitation. If in the follow-up angiography moderate or severe vasospasm was detected, hypertensive hypervolemic therapy was started (mean blood pressure $>100$ $\mathrm{mmHg}$ ). In some cases of refractory hemodynamically relevant vasospasm without evident infarction on the CT scan, continuous intra-arterial nimodipine application via micro-catheter was performed. Resolution of vasospasm was monitored by a repetitive digital subtraction angiography after at least $72 \mathrm{~h}$.

Clinical and radiological variables predictive of the presence of vasospasm. During the hospital stay, baseline demographic information, clinical and radiological findings were recorded. The incidence of angiographic and hemodynamic vasospasm in followup angiography was noted. The cerebral angiograms were interpreted by two independent neuroradiologists and were compared with those performed on admission.

The number of intra-arterial nimodipine applications because of hemodynamic vasospasm in both groups was recorded. For the neurological status, the Glasgow Coma Scale (34) and the initial Hunt and Hess grade (35) were collected. The initial CT scan was used to determine the severity of bleeding by using the Barrow Neurological Institute Scale (BNI) (36). The location of the aneurysm and the treatment strategy was determined. The clinical outcome was measured by using the Glasgow Outcome Scale (GOS) (37), the modified Rankin Scale (mRS) (38) and the National Institute of Health Stroke Scale (NIHSS) (39).

TCD examination. At day 1 after the hemorrhage, daily TCD examination was performed for most patients. TCD data were collected prospectively in the ICU and noted in a computerized database. TCD was conducted between 10 am and $4 \mathrm{pm}$. The mean blood flow of the middle cerebral artery was measured on both sides 
Table I. Demographic characteristics according to oral administration of nimodipine in 179 patients with aneurysmal subarachnoid hemorrhage.

\begin{tabular}{|c|c|c|c|}
\hline \multirow[b]{2}{*}{ Variable } & \multicolumn{2}{|c|}{ Nimodipine } & \multirow[b]{2}{*}{$p$-Value } \\
\hline & $\begin{array}{c}\text { With oral } \\
(\mathrm{n}=74)\end{array}$ & $\begin{array}{l}\text { Without oral } \\
\quad(n=105)\end{array}$ & \\
\hline \multicolumn{4}{|l|}{ Age, years } \\
\hline Median (range) & $55(32-82)$ & $54(27-86)$ & 0.723 \\
\hline \multicolumn{4}{|l|}{ Gender, $\mathrm{n}$} \\
\hline Male & 26 & 40 & 0.7539 \\
\hline Women & 48 & 65 & 0.7539 \\
\hline \multicolumn{4}{|c|}{ Localisation of aneurysm, } \\
\hline Posterior & 23 & 25 & 0.2795 \\
\hline Anterior & 51 & 80 & 0.2795 \\
\hline \multicolumn{4}{|l|}{ Method, n } \\
\hline Clipping & 21 & 49 & 0.0135 \\
\hline Coiling & 53 & 56 & 0.0135 \\
\hline \multicolumn{4}{|c|}{ Hunt \& Hess grade, $n$} \\
\hline 1 & 35 & 34 & \\
\hline 2 & 15 & 16 & \\
\hline 3 & 4 & 11 & \\
\hline 4 & 4 & 9 & \\
\hline 5 & 16 & 34 & \\
\hline \multicolumn{4}{|l|}{ BNI grade, $\mathrm{n}$} \\
\hline I & 8 & 4 & \\
\hline II & 41 & 52 & \\
\hline III & 18 & 31 & \\
\hline IV & 4 & 12 & \\
\hline $\mathrm{V}$ & 3 & 5 & \\
\hline
\end{tabular}

BNI: Barrow Neurological Institute Scale.

through the transtemporal window. A 2-MHz handheld transducer probe (Multi-Dop ${ }^{\circledR} \mathrm{T}$ digital) was used. The depth of insonation for the middle cerebral artery was between 50 and $60 \mathrm{~mm}$. When there was no presence of vasospasm (angiographic or hemodynamic) in the follow-up angiography, TCD examination was stopped.

Statistical analysis. A standard statistical software package for data analysis was used (GraphPad Prism 8; GraphPad Software, Inc., La Jolla, CA, USA).

The two groups were checked for comparability of demographic and clinical variables at entry by a chi-square test for categorical variables. In the analysis of outcome (GOS, mRS and NIHSS), BNI grade and Hunt and Hess grade, a two-tailed Mann-Whitney $U$-test was used. For the incidence of macro-vasospasm (angiographic and its hemodynamic relevance), treatment modality, location of the aneurysm and mortality, a two-tailed chi-square/Fisher's exact test was performed.

Values of $p<0.05$ were considered significant.

\section{Results}

In cohort 1,74 patients $(67.2 \%)$ out of 100 with aSAH were included. In cohort 2, 105 patients $(73.4 \%)$ out of 143 with aSAH were included. The most common reason for
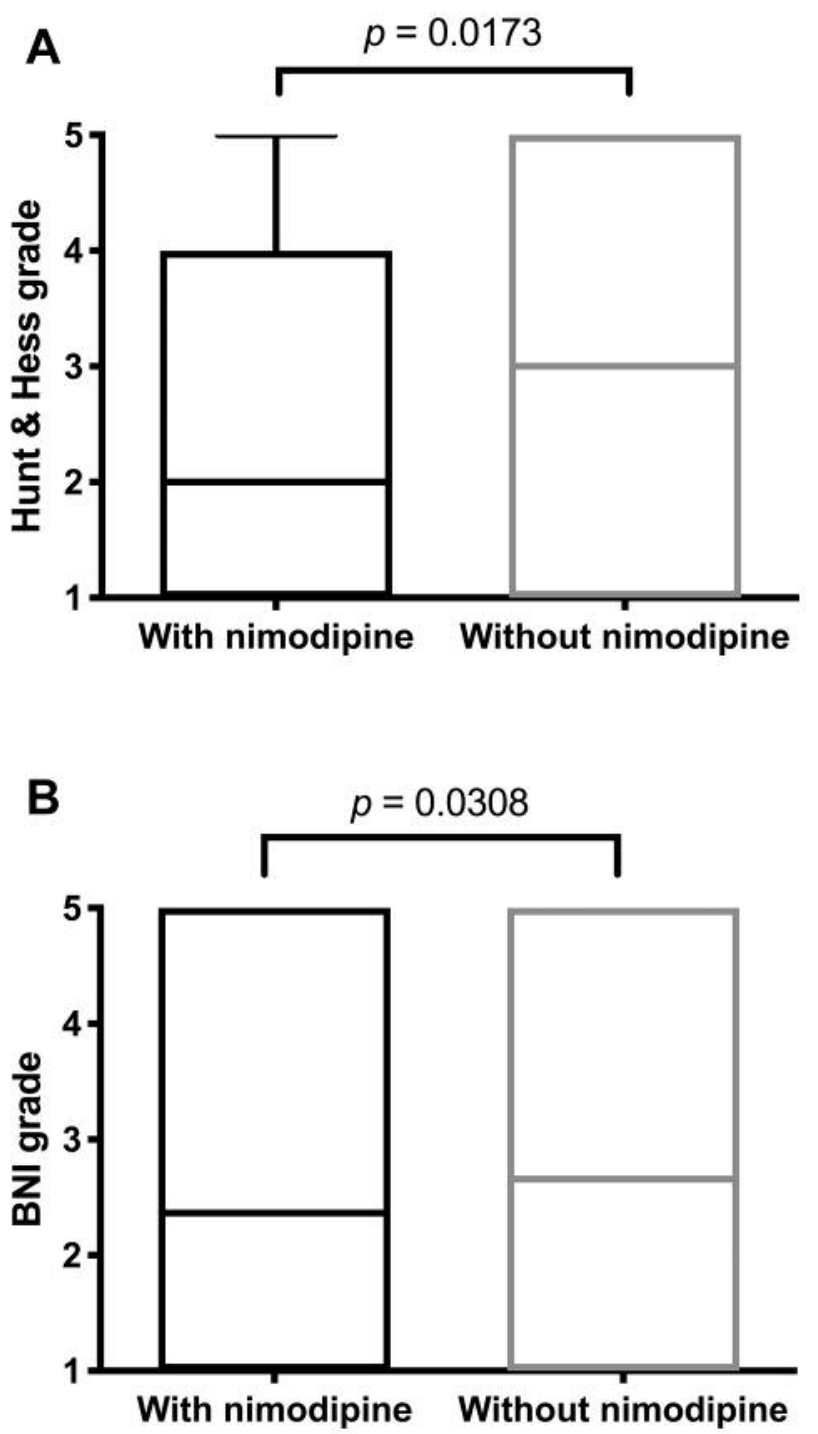

Figure 1. Distribution of the Hunt and Hess grade (A) and the Barrow Neurological Institute Scale (BNI) grade (B) between groups treated with (cohort 1) and without (cohort 2) oral nimodipine. The minimum and maximum are shown, as well as the median of both groups.

exclusion was no treatment because of poor initial condition $(n=42)$. In 21 patients, no follow-up angiography was performed. Eleven patients died within the first 3 days. In cohort 1 , there were 48 women $(65 \%)$ and 26 men $(35 \%)$; the median age was 55 years. In cohort 2 , there were 65 women $(62 \%)$ and 40 men $(38 \%)$; the median age was 54 years. Patient groups were comparable for age and sex.

Treatment modality of the aneurysm was significantly different between both groups, with significantly more frequent use of coiling in cohort 1 (72\% vs. 53\%) and clipping in cohort 2 (47\% vs. 28\%, $p=0.0135)$. Most patients in cohort 

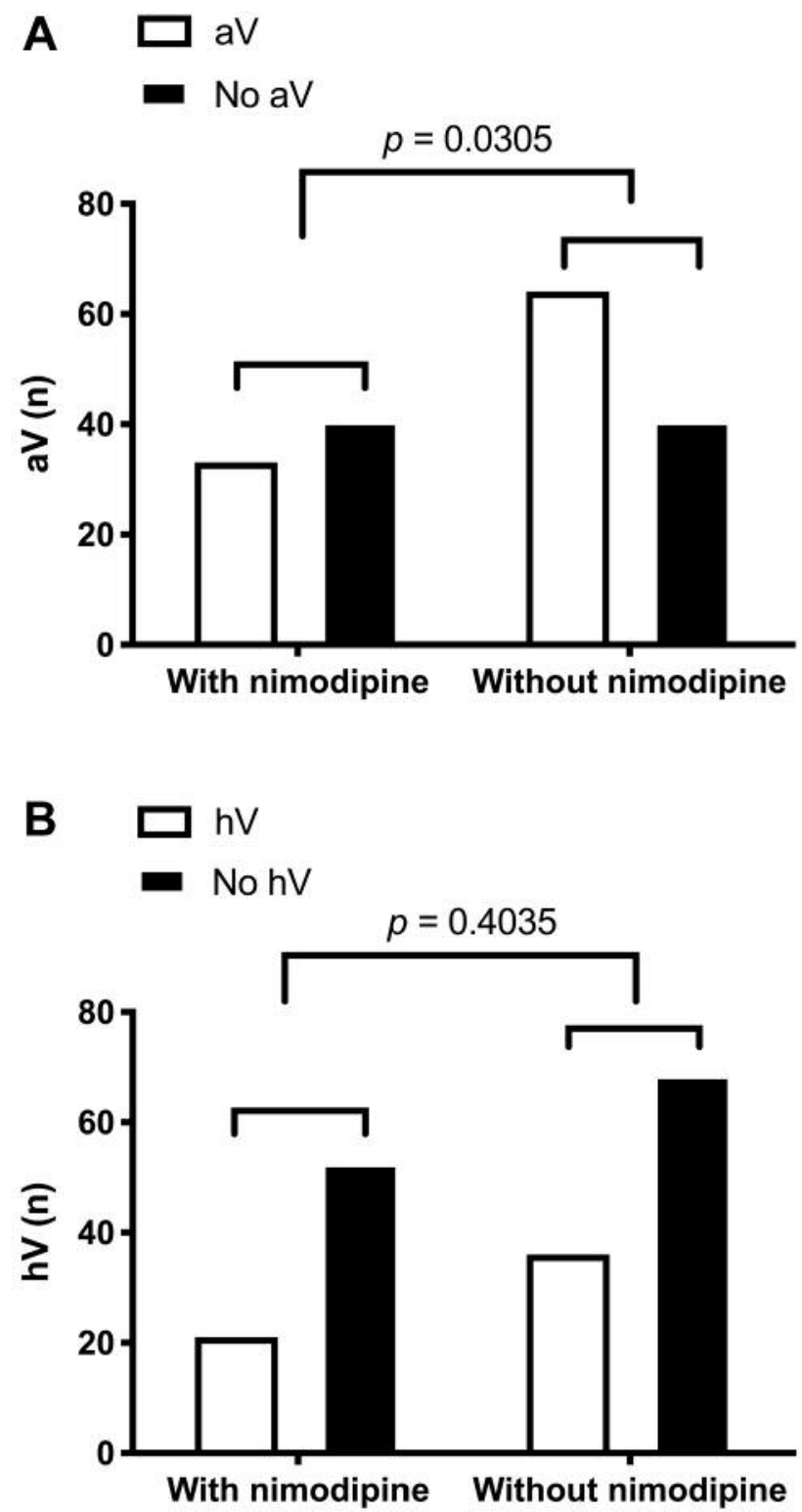

Figure 2. Number of patients ( $n$ ) developing an angiographic (aV) (A) or hemodynamic vasospasm $(\mathrm{hV})(\mathrm{B})$ in groups treated with (cohort 1) and without (cohort 2) oral nimodipine. Significantly fewer patients administered nimodipine orally had aV. No significant difference in the occurrence of $h V$ regardless whether nimodipine was used was found.

1 were treated endovascularly, whereas in patients of cohort 2 , the use of these techniques was balanced (Table I).

The mean Hunt and Hess grade $(p=0.0173)$ as well as the BNI grade $(p=0.0308)$ were significantly different between the two groups (Figure 1). There were more patients with a Hunt and Hess grade 4 and 5 as well as a BNI grade 3 and 4 in cohort 2 (Table I). In our study, we saw a significant
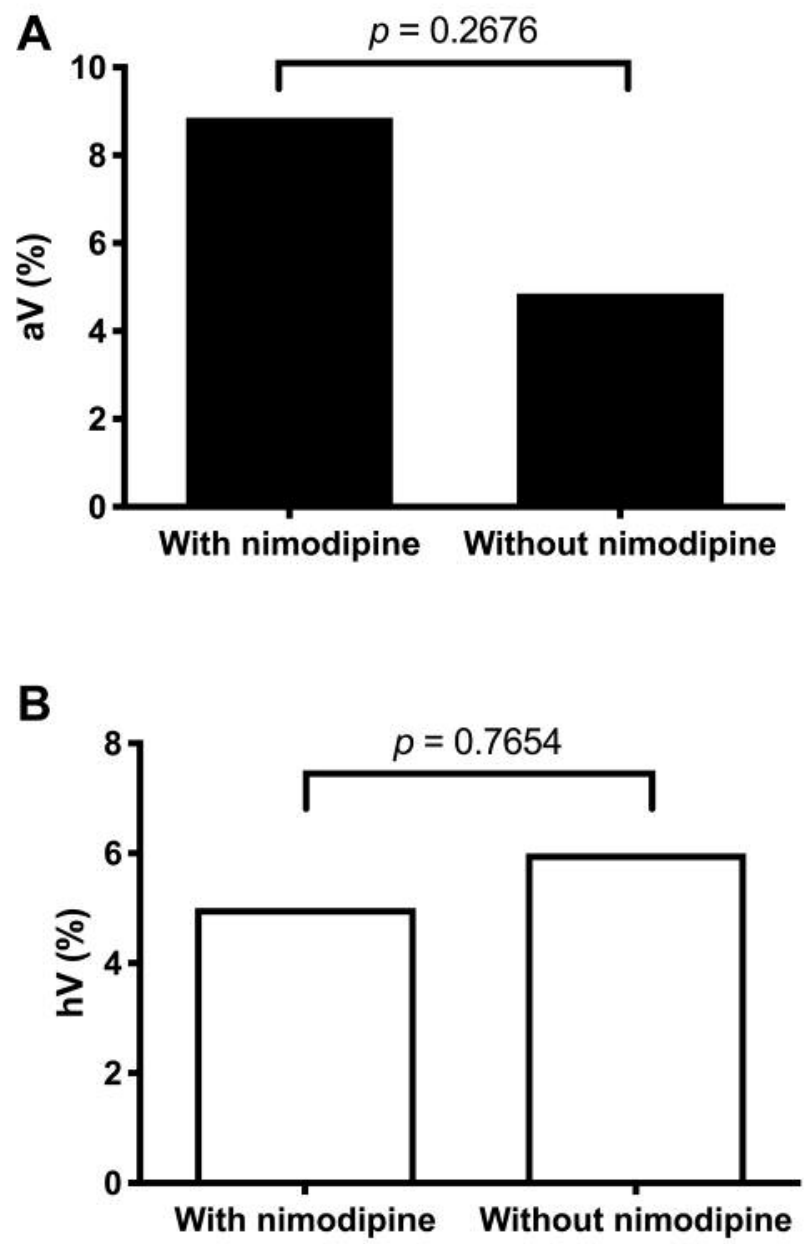

Figure 3. Frequency of developing an angiographic (aV) (A) or hemodynamic vasospasm $(\mathrm{hV})(\mathrm{B})$ after 10 days or more after initial bleeding in groups treated with (cohort 1) and without (cohort 2) oral nimodipine. A tendency for delayed $a V$ was found when oral nimodipine was administered. There was no significant difference in the total occurrence of $a V$ between the groups. No difference in occurrence of $h V$ was detected $(B)$.

difference in the incidence of angiographic vasospasm between groups (cohort 1: $43.2 \%$ vs. cohort 2: $61 \%$; $p=0.0305)$, but there was no significant difference in the incidence of hemodynamically relevant vasospasm between both groups (cohort 1: $28.4 \% v s$. cohort 2: $34.3 \%, p=0.4035$ ) (Figure 2).

A tendency for delay in angiographic vasospasm was shown in cohort 1 versus cohort $2(9.4 \%$ vs. $4.7 \%$ at $8 \pm 2$ days; $p=0.2625)$. No significant change in the temporal occurrence of hemodynamic vasospasm between the two groups was noted ( $p=0.7369$ ) (Figure 3 ).

The number of intra-arterial nimodipine applications was equivalent in both groups (cohort 1: 22.9\%; cohort 2: 
Table II. Number of patients ( $n$ ) administered intra-arterial nimodipine application.

\begin{tabular}{lccc}
\hline Variable & With oral nimodipine & Without oral nimodipine & $p$-Value \\
\hline Intra-arterial nimodipine application, $n$ & 17 & 23 & 0.8658 \\
No intra-arterial nimodipine application, $\mathrm{n}$ & 57 & 82 & 0.8658 \\
\hline
\end{tabular}

$21.9 \%$ ). Because of angiographic vasospasm, an intra-arterial nimodipine application was performed in only one case in cohort 1 . In all other cases, there was a hemodynamically relevant vasospasm detected in the angiography (Table II).

There was no significant difference in morbidity and mortality between the groups (cohort 1: $14.8 \% \mathrm{vs}$. cohort 2: $10.5 \%, p=0.3785)$. But a trend for a better outcome in the cohort 1 nimodipine group was shown (Figure 4). In the more detailed analyses of the clinical outcome via $\mathrm{mRS}$ and NIHSS, a significant improvement in cohort 1 was shown (Figure 5).

\section{Discussion}

If patients with an aSAH survive the first episode of their disease, delayed cerebral ischemia caused by vasospasm is now well recognized as the leading cause of poor outcome $(40,41)$. The cause is still unexplained and the importance of the different mechanisms involved remains unclear. Different starting points to solve that question and to improve outcome have been tried. Most treatments met with either limited or no success (42). For many years, one established procedure for enhancing the cerebral blood flow in patients with symptomatic vasospasm is hypertensive hypervolemic therapy. Another is the wide variety of pharmacological agents; the most important drug class is that of the calcium antagonists. These substances have a vasodilatory effect on cerebral blood vessels. The first to show this were Allen and Bahr in 1979 (43). They were able to dilate cerebral blood vessels in dogs by giving them oral nifedipine. Another group showed a dilatory effect on pial arterioles of perivascular application in cats (44). Another calcium antagonist is nimodipine. It has some advantages over nifedipine. Firstly, it is lipid-soluble, enabling it to more effectively cross the blood-brain barrier SecondIy, it is a more potent cerebral vasodilatator. The first study showing a potential benefit of orally administered nimodipine in patients with aSAH was a multicenter trial conducted by Allen et al. in 1983 (18). Only patients with $\mathrm{SAH}$ of a good clinical grade were included. In this patient collective, a significant reduction of poor outcome was shown. Since then several trials were initiated to confirm these results. A possible positive effect of oral nimodipine on the prevention of DCI and on the outcome in patients after aSAH was demonstrated (16-27). Even neuroprotection via reduction of calcium-mediated excitotoxicity is described (28). But there are several critical points to discuss: Most of the studies have only included patients with good grade (Hunt and Hess grade I-III). There has only been one trial (110 patients with a Hunt and Hess grade of IV-V) which included all patients with aSAH irrespective of clinical severity (21). The results showed that oral nimodipine administration increased the proportions of patients with good neurological outcome and a decrease in those developing delayed ischemic deficits caused by vasospasm. This was seen primarily in patients with Hunt and Hess grade III and IV. In patients with grade V, administration of nimodipine had no positive influence on the outcome. In addition, a heterogeneity of nimodipine dosage (from 60-90 mg every $4 \mathrm{~h}$ ), treatment days (9-21 days) and application form (oral or intravenous) was found. The most frequent application form was oral, with a dosage of $60 \mathrm{mg}$ nimodipine every $4 \mathrm{~h}$. Intravenous administration of calcium antagonists, which is more expensive and has a substantial risk of induced hypotension, should only be used in exceptional cases (45). So our patients also received their dosage orally. Another important thing is that the patients received their medication at admission. Therefore, the first administration of nimodipine took place at the neuro-intensive care unit; the administration lasted 21 days.

Another opportunity for preventing delayed cerebral ischemia and improving the outcome in patients with aSAH is the intrathecal application of calcium antagonist pellets. This procedure is much more complex and only an option for patients who are treated surgically by clipping. For this special form of application, only few studies were initiated, with promising results in regard to the present of symptomatic vasospasm and overall outcome $(46,47)$.

Most of the studies dealing with the positive effect of nimodipine were initialized at the end of the 1980s and early 1990s. At that time, the surgical part for the elimination of aneurysm was preferred. Endovascular techniques have been increasingly developed. Nowadays, in most cases, endovascular treatment such as coiling or stenting for patients with aSAH is privileged due to minor complications. Perhaps this less invasive treatment modality for aneurysm minimizes stress on intracranial blood vessels and the incidence of symptomatic vasospasm is less. Even an intra-arterial application of nimodipine via micro-catheter to prevent vasospasm is possible and has positive results (30-33). 

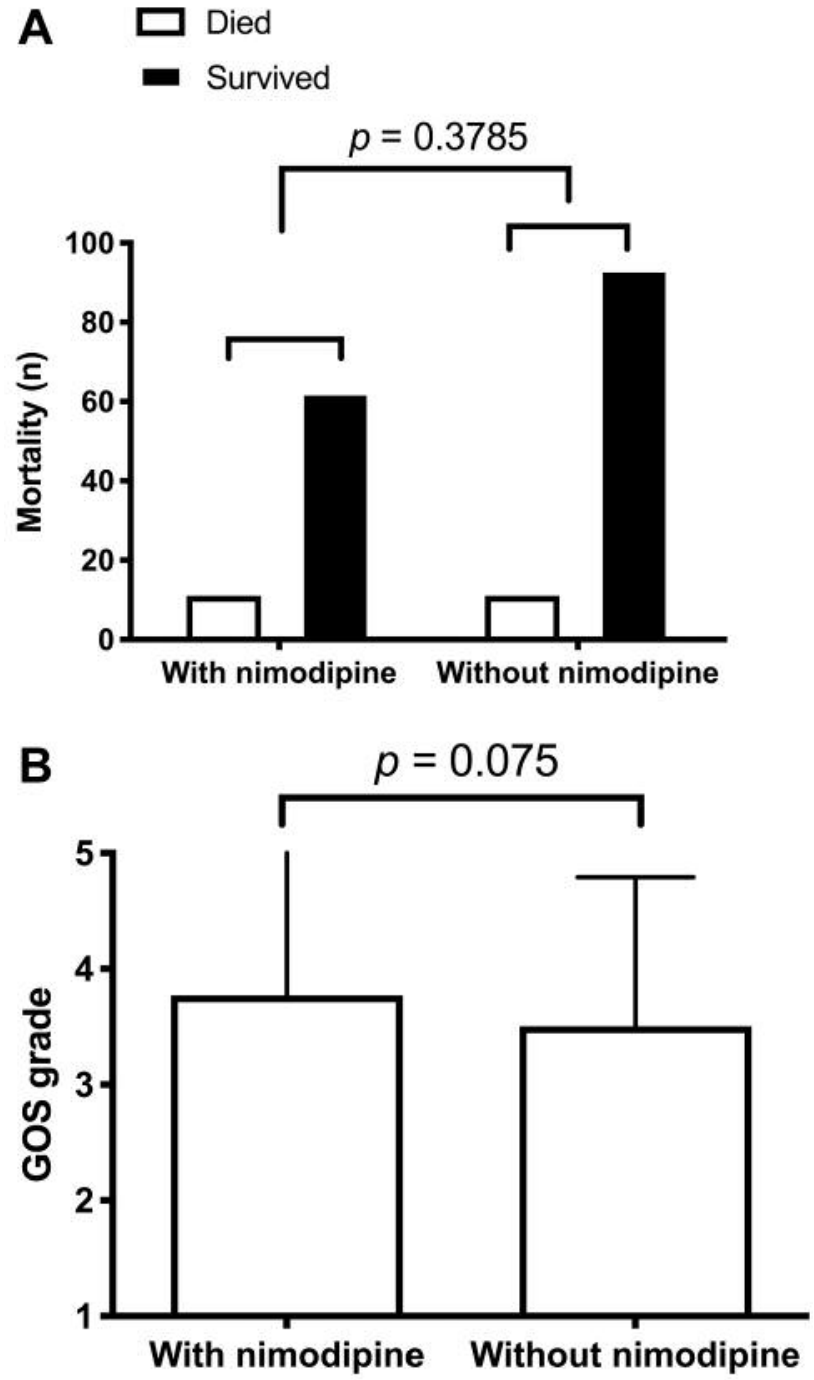

Figure 4. A: Number of patients ( $n$ ) in groups treated with (cohort 1) and without (cohort 2) oral nimodipine who died during their hospital stay. B: Distribution of the Glasgow Outcome Scale (GOS) in both groups. Median values are shown. A tendency for better outcome in the nimodipine group is shown.

In our study, an imbalance in favor of endovascular treatment was seen. Although the oral administration of nimodipine between the two groups was strictly separated (cohort 1: $60 \mathrm{mg}$ nimodipine orally every $4 \mathrm{~h}$ at admission for 3 weeks, cohort 2: no administration of oral nimodipine), intra-arterial nimodipine application via micro-catheter was performed if refractory hemodynamic vasospasm was detected in the cerebral angiography. That might be a reason why we were unable to find any difference in the overall outcome between the groups (mortality cohort 1: $14.8 \%$, cohort 2: $10.5 \%, p=0.3785$ ) but there was a tendency for a
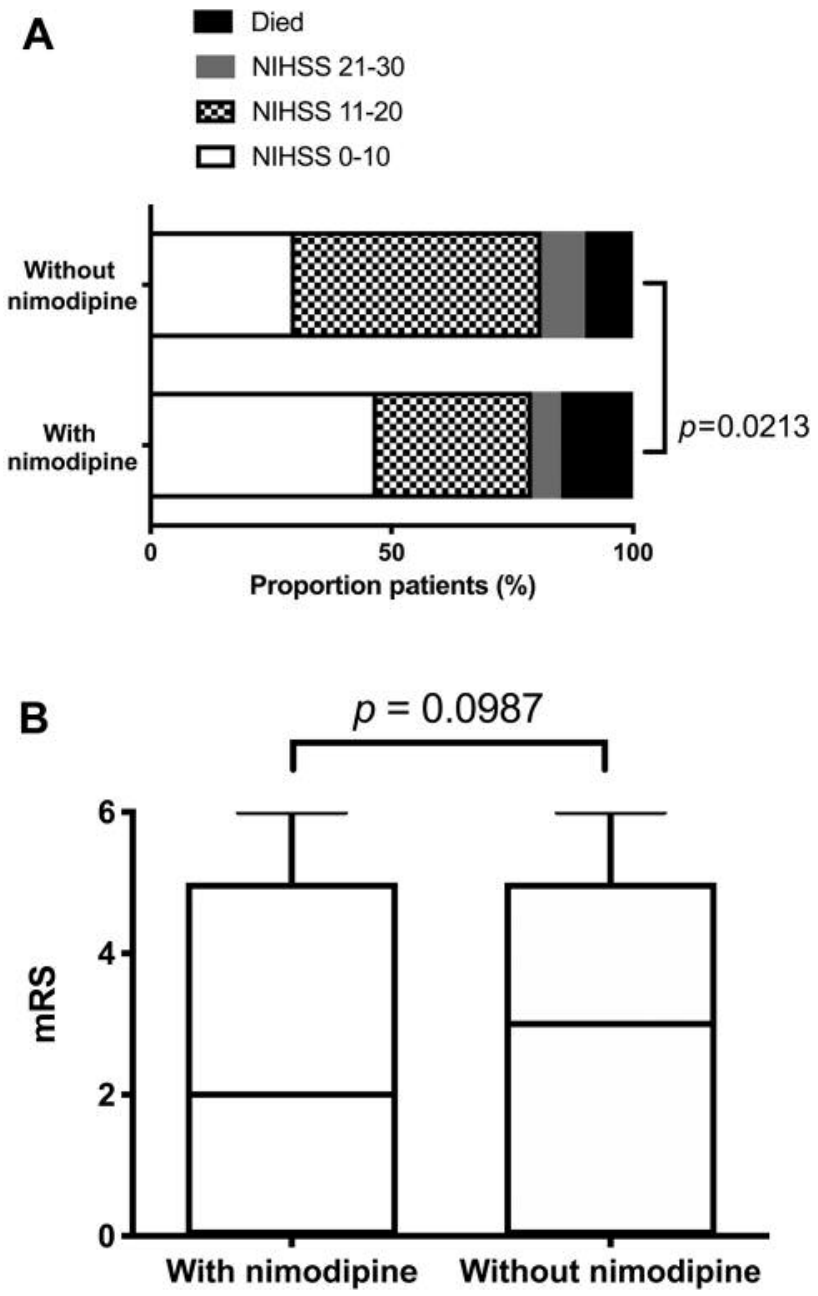

Figure 5. Distribution of the National Institute of Health Stroke Scale (NIHSS) (A) and the Modified Ranking Scale (mRS) (B) in groups treated with (cohort 1) and without (cohort 2) oral nimodipine. Better clinical outcome was shown by significant difference in the NIHSS in the group treated with oral nimodipine. No significant difference could be shown measured by the $\mathrm{mRS}$; but tendency to better outcome with oral nimodipine administration. Data in $(B)$ are minimum and maximum, as well as the median are shown.

better GOS in cohort $1(p=0.075)$. In the more detailed analyses of clinical outcome measured by NIHSS, a significantly better outcome in cohort 1 was detected $(p=0.0213)$. This might be a result of the neuroprotective effect of nimodipine itself and the improvement of microcirculation.

The Hunt and Hess grade was significantly different between the two groups $(p=0.0173)$. There were more patients with Hunt and Hess grade 4 and 5 in cohort 2 . This might explain the tendency of better GOS in the nimodipine group. 
The BNI grade was used to determine the amount of initial bleeding. Here we found a significant difference between the two groups $(p=0.0308)$. There were more patients with a BNI grade III-IV in cohort 2 (patients without oral nimodipine administration). The BNI grade reflects the probability of developing symptomatic vasospasm. The higher the BNI grade, the more likely the occurrence of symptomatic vasospasm (BNI grade V: $50 \%$ probability of symptomatic vasospasm after aSAH) (36). That might explain the significant difference in the appearance of angiographic vasospasm (43.2\%; vs. 61\%; $p=0.0305$ ) and the tendency for better GOS in cohort 1 . No difference in the incidence of hemodynamic vasospasm was not seen (cohort 1: $28.4 \%$ vs. cohort 2: $34.3 \%, p=0.4035$ ). An explanation for the nearly equal occurrence of vasospasm in both groups may be that previous animal and clinical trials reported that nimodipine does not have an effect on large vessel diameter $(21,48-50)$. Nimodipine operates on small-resistance vessels and these are not visualized in cerebral angiography (51).

In the occurrence of angiographic vasospasm over time we noticed an interesting finding. There seemed to be a rearward shift in time in the occurrence of vasospasm due to the administration of nimodipine, although not significant. Although the present study has limitations (e.g. the study sample was of moderate size and was a single-centre study), oral nimodipine still improved clinical outcome after aSAH in our patient collective.

Overall, according to current treatment guidelines of patients with an aneurysmal subarachnoid hemorrhage, in our study, oral nimodipine appeared to have a high relevance to overall outcome and should be administered routinely in that disease.

\section{Conclusion}

Many studies have shown a positive effect on outcome and delayed cerebral ischemia in patients with aSAH due to oral nimodipine treatment, therefore the administration of nimodipine is routinely performed at most neurosurgical departments. Treatment of patients with aSAH has changed, in particular because of improved endovascular techniques.

In our patient collective, oral nimodipine reduced the incidence of angiographic vasospasm; there was no influence on hemodynamic vasospasm. Angiographic vasospasm seemed to emerge later during oral nimodipine application. Overall, oral nimodipine still improved clinical outcome in this patient collective and should be available for all patients regardless of clinical severity after aSAH.

\section{Conflicts of Interest}

The Authors declare that they have no conflicts of interest in regard to this study.

\section{Authors' Contributions}

Gregory Ehrlich: Study conception and design, drafting of the article, acquisition of data, analysis and interpretation of data. Thomas Kirschning: Critical revision. Holger Wenz: Critical revision, Analysis and interpretation of data. Aldemar Andres Hegewald: Critical revision. Eva-Neumaier-Probst: Critical revision. Marcel Seiz-Rosenhagen: Study conception and design, drafting of article, critical revision, analysis and interpretation of data.

\section{References}

1 van Gijn J, Kerr RS and Rinkel GJ: Subarachnoid haemorrhage. Lancet 369: 306-318, 2007. PMID: 17258671. DOI: 10.1016/ S0140-6736(07)60153-6

2 Sarrafzadeh A, Haux D, Sakowitz O, Benndorf G, Herzog H, Kuechler I and Unterberg A: Acute focal neurological deficits in aneurysmal subarachnoid hemorrhage: Relation of clinical course, CT findings, and metabolite abnormalities monitored with bedside microdialysis. Stroke 34: 1382-1388, 2003. PMID: 12750537. DOI: 10.1161/01.STR.0000074036.97859.02

3 Charpentier C, Audibert G, Guillemin F, Civit T, Ducrocq X, Bracard S, Hepner H, Picard L and Laxenaire MC: Multivariate analysis of predictors of cerebral vasospasm occurrence after aneurysmal subarachnoid hemorrhage. Stroke 30: 1402-1408, 1999. PMID: 10390314. DOI: 10.1161/01.str.30.7.1402

4 Rabinstein A-A, Friedman JA, Weigand SD, McClelland RL, Fulgham JR, Manno EM, Atkinson JL and Wijdicks EF: Predictors of cerebral infarction in aneurysmal subarachnoid hemorrhage. Stroke 35: 1862-1866, 2004. PMID: 15218156. DOI: 10.1161/01.STR.0000133132.76983.8e

5 Suarez JI, Qureshi AI, Yahia AB, Parekh PD, Tamargo RJ, Williams MA, Ulatowski JA, Hanley DF and Razumovsky AY: Symptomatic vasospasm diagnosis after subarachnoid hemorrhage: Evaluation of transcranial Doppler ultrasound and cerebral angiography as related to compromised vascular distribution. Crit Care Med 30: 1348-1355, 2002. PMID: 12072693. DOI: 10.1097/00003246-200206000-00035

6 Fisher CM, Kistler JP and Davis JM: Relation of cerebral vasospasm to subarachnoid hemorrhage visualized by computerized tomographic scanning. Neurosurgery 6: 1-9, 1980. PMID: 7354892. DOI: 10.1227/00006123-198001000-00001

7 Duff TA, Louie J, Feilbach JA and Scott G: Erythrocytes are essential for development of cerebral vasculopathy resulting from subarachnoid hemorrhage in cats. Stroke 19: 68-72, 1988. PMID: 3336905. DOI: 10.1161/01.str.19.1.68

8 Mac Donald RL, Weir BKA, Runzer TD, Grace MGA, Findlay JM, Saito K, Cook DA, Mielke BW and Kanamaru K: Etiology of cerebral vasospasm in primate. J Neurosurg 75: 415-424, 1991. PMID: 1869943. DOI: 10.3171/jns.1991.75.3.0415

9 Shishido T, Suzuki R, Qian L and Hirakawa K: The role of superoxide anions in the pathogenesis of cerebral vasospasm. Stroke 25: 864-868, 1994. PMID: 8160234. DOI: 10.1161/ 01.str.25.4.864

10 Fergusen S and Macdonald RL: Predictors of cerebral infarction in patients with aneurysmal subarachnoid hemorrhage. Neurosurgery 60: 658-667, 2007. PMID: 17415202. DOI: 10.1227/01.NEU.0000255396.23280.31

11 Lasner TM, Weil RJ, Riina HA, King JT Jr, Zager EL, Raps EC and Flamm ES: Cigarette smoking-induced increase in the risk 
of symptomatic vasospasm after aneurysmal subarachnoid hemorrhage. J Neurosurg 87: 381-384, 1997. PMID: 9285602. DOI: $10.3171 /$ jns.1997.87.3.0381

12 Rabb CH, Tang G and Chin LS: A statistical analysis of factors related to symptomatic cerebral vasospasm. Acta Neurochir 127: 27-31, 1994. PMID: 7942177.

13 Van den Bergh WM, Algra A, Van der Sprenkel JWB, Tulleken CAF and Rinkel GJE: Hypomagnesemia after aneurysmal subarachnoid hemorrhage. Neurosurgery 52: 276281, 2003. PMID: 12535355. DOI: 10.1227/01.neu.00 $00043984.42487 .0 \mathrm{e}$

14 Veyna RS, Seyfried D, Burke DG, Zimmermann C, Mlynarek M, Nichols V, Marrocco A, Thomas AJ, Mitsias PD and Malik GM: Magnesium sulfate therapy after aneurysmal subarachnoid hemorrhage. J Neurosurg 96: 510-514, 2002. PMID: 11883835. DOI: $10.3171 /$ jns.2002.96.3.0510

15 Van den Bergh WM, on behalf of the MASH study group: Magnesium sulfate in aneurysmal subarachnoid hemorrhage: a randomized controlled trial. Stroke 36: 1011-1015, 2005. PMID: 15790946. DOI: 10.1161/01.STR.0000160801.96998.57

16 Pickard JD, Murray GD, Illingworth R, Shaw MD, Teasdale GM, Foy PM, Humphrey PR, Lang DA, Nelson R, Richards P, Sinar J, Bailey S and Skene A: Effect of oral nimodipine on cerebral infarction and outcome after subarachnoid haemorrhage: British Aneurysm Nimodipine Trial. BMJ 298: 636-642, 1989. PMID: 2496789. DOI: 10.1136/bmj.298.6674.636

17 Dorhout Mees SM, Rinkel GJ and Feigin VL: Calcium antagonists for aneurysmal subarachnoid haemorrhage. Cochrane Database Syst Rev 3: CD000277, 2007. PMID: 17143226. DOI: 10.1227/01.NEU.0000249031.26372.13

18 Allen GS, Ahn HS, Preziosi TJ, Battye R, Boone SC, Boone SC, Chou SN, Kelly DL, Weir BK, Crabbe RA, Lavik PJ, Rosenbloom SB, Dorsey FC, Ingram CR, Mellits DE, Bertsch LA, Boisvert DP, Hundley MB, Johnson RK, Strom JA and Transou CR: Cerebral arterial spasm: A controlled trial of nimodipine in patients with sub- arachnoid hemorrhage. N Engl J Med 308(11): 619-624, 1983. PMID: 6338383. DOI: 10.1056/NEJM198303173081103

19 Karinen P, Koivukangas P, Ohinma-a A, Koivukangas J and Ohman J: Cost-effectiveness analysis of nimodipine treatment after aneurysmal subarachnoid hemorrhage and surgery. Neurosurgery 45(4): 780-785, 1999. PMID: 10515471. DOI: 10.1097/00006123-199910000-00009

20 Philippon J, Grob R and Dagreou F: Prevention of vasospasm in subarachnoid haemorrhage. A controlled study with nimodipine. Acta Neurochir 82(3-4): 110-114, 1986. PMID: 3538789.

21 Petruk KC, West M and Mohretal G: Nimodipine treatment in poor-grade aneurysm patients. Results of a multicenter doubleblind placebo-controlled trial. J Neurosurg 68(4): 505-517, 1988. PMID: 3280746. DOI: 10.3171/jns.1988.68.4.0505

22 Mee E, Dorrance D, Lowe D and Neil-Dwyer G: Controlled study of nimodipine in aneurysm patients treated early after subarachnoid hemorrhage. Neurosurgery 22(3): 484-491, 1988. PMID: 3283595. DOI: 10.1227/00006123-198803000-00006

23 Ohman J and Heiskanen O: Effect of nimodipine on the outcome of patients after aneurysmal subarachnoid hemorrhage and surgery. J Neurosurg 69(5): 683-686, 1988. PMID: 3054010. DOI: $10.3171 /$ jns.1988.69.5.0683

24 Harders A, Kakarieka A and Bra-akman R: Traumatic subarachnoid hemorrhage and its treatment with nimodipine. J
Neurosurg 85(1): 82-89, 1996. PMID: 8683286. DOI: $10.3171 /$ jns.1996.85.1.0082

25 Jan M, Buchheit $\mathrm{F}$ and Tremoulet M: Therapeutic trial of intravenous nimodipine in patients with established cerebral vasospasm after rupture of intracranial aneurysms. Neurosurgery 23(2): 154-157, 1988. PMID: 3054619. DOI: 10.1227/0000 6123-198808000-00004

26 Ohman J, Servo A and Heiskanen O: Long-term effects of nimodipine on cerebral infarcts and outcome after aneurysmal subarachnoid hemorrhage and surgery. J Neurosurg 74(1): 8-13, 1991. PMID: 1984511. DOI: 10.3171/jns.1991.74.1.0008

27 Messeter K, Brandt L, Ljunggren B, Svendga-ard NA, Algotsson L, Romner B and Ryding E: Prediction and prevention of delayed ischemic dysfunction after aneurysmal subarachnoid hemorrhage and early operation. Neurosurgery 20(4): 548-553, 1987. PMID: 3587545. DOI: 10.1227/00006123-198704000-00007

28 Feigin VL, Rinkel GJE, Algra A, Vermeulen M and Van Gijn J: Calcium antagonists in patients with aneurysmal subarachnoid hemorrhage: a systematic review. Neurology 50(4): 876-883, 1998. PMID: 9566366. DOI: 10.1212/wnl.50.4.876

29 McDougall CG, Spetzler RF, Zabramski JM, Partovi S, Hills NK, Nakaji $\mathrm{P}$ and Albuquerque FC: The barrow ruptured aneurysm trial. J Neurosurg 116(1): 135-144, 2012. PMID: 22054213. DOI: $10.3171 / 2011.8$.JNS 101767

30 Biondi A, Ricciardi GK, Puybasset L, Abdennour L, Longo M, Chiras $\mathrm{J}$ and Van Effenterre R: Intra-arterial nimodipine for the treatment of symptomatic cerebral vasospasm after aneurysmal subarachnoid hemorrhage: Preliminary results. Am J Neuroradiol 25: 1067-1076, 2004. PMID: 15205150.

31 Boker DK, Solymosi L and Wassmann H: Immediate postangiographic intra-arterial treatment of cerebral vasospasm after subarachnoid hemorrhage with nimodipine: Report on 3 cases. Neurochirurgia 28(1): 118-120, 1985. PMID: 4010867. DOI: $10.1055 / \mathrm{s}-2008-1054116$

32 Grotenhuis JA, Bettag W, Fiebach BJ and Dabir K: Intracarotid slow bolus injection of nimodipine during angiography for treatment of cerebral vasospasm after SAH: A preliminary report. J Neurosurg 61: 231-240, 1984. PMID: 6737047. DOI: $10.3171 /$ jns.1984.61.2.0231

33 Dehdashti AR, Binaghi S, Uske A and Regli L: Intra-arterial nimodipine for the treatment of symptomatic vasospasm after aneurysmal subarachnoid hemorrhage: a preliminary study. Neurol India 59(6): 810-816, 2011. PMID: 22234190. DOI: 10.4103/0028-3886.91356

34 Jones C: Glasgow coma scale. Am J Nurs 79(9): 1551-1553, 1979. PMID: 6911501.

35 Hunt WE, Meagher JN and Hess RM: Intracranial aneurysm. A nine-year study. Ohio State Med J 62(11): 1168-1171, 1966. PMID: 5979493

36 Wilson DA, Nakaji P, Abla A-A, Uschold TD, Fusco DJ, Oppenlander ME, Albuquerque FC, McDougall CG, Zabramski JM and Spetzler RF: A simple and quantitative method to predict symptomatic vasospasm after subarachnoid hemorrhage based on computed tomography: beyond the Fisher scale. Neurosurgery 71(4): 869-875, 2012. PMID: 22801639. DOI: 10.1227/NEU.0b013e318267360f

37 Jennett B, Snoek J, Bond MR and Brooks N: Disability after severe head injury: observations on the use of the Glasgow Outcome Scale. J Neurol Neurosurg Psychiatry 44(4): 285-293, 1981. PMID: 6453957. DOI: 10.1136/jnnp.44.4.285 
38 Burn JP: Reliability of the modified Rankin scale. Stroke 23(3): 438, 1992. PMID: 1610453.

39 Goldstein LB, Bertels C and Davis JN: Interrater reliability of the NIH stroke scale. Arch Neurol 46(6): 660-662, 1989. PMID: 2730378. DOI: 10.1001/archneur.1989.00520420080026

40 Adams HP Jr, Kassell NF, Torner JC and Haley EC Jr: Predicting cerebral ischemia after aneurysmal subarachnoid hemorrhage: influences of clinical condition, CT results, and antifibrinolytic therapy. A report of the Cooperative Aneurysm Study. Neurology 37: 1586-1591, 1987. PMID: 3658161. DOI: $10.1212 /$ wnl.37.10.1586

41 Ljunggren B, Säveland H and Brandt L: Causes of unfavorable outcome after early aneurysm operation. Neurosurgery 13: 629633, 1983. PMID: 6657014. DOI: 10.1227/00006123-198312 000-00001

42 Wilkins RH: Attempts at prevention or treatment of intracranial arterial spasm: an update. Neurosurgery 18: 808-825, 1986. PMID: 3526171. DOI: 10.1227/00006123-198606000-00026

43 Allen GS and Bahr AL: Cerebral arterial spasm: Part 10. Reversal of acute and chronic spasm in dogs with orally administered nifedipine. Neurosurgery 4: 43-47, 1979. PMID: 450214. DOI: $10.1227 / 00006123-197901000-00008$

44 Brandt L, Andersson KE, Bengtsson B, Edvinsson B, Ljunggren $\mathrm{B}$ and MacKenzie ET: Effects of nifedipine on pial arteriolar calibre: An in vivo study. Surg Neurol 12: 49-352, 1979. PMID: 515931.

45 Haley EC, Kassell NF and Torner J: A randomized controlled trial of high-dose intravenous nicardipine in aneurysmal subarachnoid hemorrhage. A report of the Cooperative Aneurysm Study. J Neurosurg 78: 537-547, 1993. PMID: 8450326. DOI: $10.3171 /$ jns.1993.78.4.0537

46 Etminan N, Macdonald RL, Davis C, Burton K, Steiger HJ and Hänggi D: Intrathecal application of the nimodipine slow-release microparticle system EG-1962 for prevention of delayed cerebral ischemia and improvement of outcome after aneurysmal subarachnoid hemorrhage. Acta Neurochir Suppl 120: 281-286, 2015. PMID: 25366637. DOI: 10.1007/978-3-319-04981-6_47
47 Barth M, Pena P, Seiz M, Thomé C, Muench E, Weidauer S, Hattingen E, Kasuya $\mathrm{H}$ and Schmiedek P: Feasibility of intraventricular nicardipine prolonged release implants in patients following aneurysmal subarachnoid haemorrhage. Br J Neurosurg 25(6): 677-683, 2011. PMID: 21344979. DOI: $10.3109 / 02688697.2010 .548878$

48 Espinosa F, Weir B, Shnitka T, Overton T and Boisvert D: A randomized placebo-controlled double-blind trial of nimodipine after SAH in monkeys. Part 2: Pathological findings. J Neurosurg 60(6): 1176-1185, 1984. PMID: 6726361. DOI: 10.3171/jns.1984.60.6.1176

49 Ljunggren B, Brandt L, Säveland H, Nilsson PE, Cronqvist S, Andersson KE and Vinge E: Outcome in 60 consecutive patients treated with early aneurysm operation and intravenous nimodipine. J Neurosurg 61(5): 864-873, 1984. PMID: 6491732. DOI: $10.3171 /$ jns.1984.61.5.0864

50 Nosko M, Weir B, Krueger C, Cook D, Norris S, Overton T and Boisvert D: Nimodipine and chronic vasospasm in monkeys: Part 1. Clinical and radiological findings. Neurosurgery 16(2): 129-136, 1985. PMID: 3974822. DOI: 10.1227/00006123198502000-00001

51 Auer LM, Oberbauer RW and Schalk HV: Human pial vascular reactions to intravenous Nimodipine-infusion during EC-IC bypass surgery. Stroke 14(2): 210-213, 1983. PMID: 6836645. DOI: $10.1161 / 01$.str.14.2.210
Received July 3, 2019

Revised September 14, 2019

Accepted September 19, 2019 